\title{
Fama e engajamento no Instagram: as celebridades e a convocação de públicos ${ }^{1}$
}

\section{Fame and engagement on Instagram: celebrities and the convocation of public}

Fernanda de Faria Medeiros²

1 A primeira versão deste texto foi apresentada no seminário Polarizações, promovido pelo Grupo de Pesquisa Mídia e Narrativa, da Pontifícia Universidade Católica de Minas Gerais (PUC Minas), em Belo Horizonte, de 3-5 de novembro de 2015. 


\section{Resumo}

Com foco no contexto atual das redes sociais brasileiras, a intenção deste trabalho é observar as possibilidades de representação dos anônimos por meio das novas formas de interlocução que se manifestam entre as celebridades e os comuns. O artigo tenta articular o conceito de público (DEWEY, 2008) com a perspectiva da constituição de públicos que se formam a partir da atuação midiática (BABO-LANÇA, 2013), a fim de analisar as investidas de representação, por parte das celebridades, em seus movimentos de convocação e de interlocução com grupos sociais específicos. Para tanto, examinamos os perfis virtuais da cantora Daniela Mercury e do rapper Emicida.

\section{Palavras-chave}

Celebridade, público, convocação, Instagram. 


\section{Abstract}

Focusing on the current context of Brazilian social networks, the intention of this work is to look at the anonymous representation possibilities through new forms of dialogue that manifest themselves among celebrities and ordinary. The article tries to articulate the concept of public (DEWEY, 2008) with the prospect of public constitution that form from the media performance (BABO-LANÇA, 2013 ) in order to analyze the onslaughts of representation by the celebrities, in his convocations of specific social groups. Therefore, we examined the virtual profiles of the singer Daniela Mercury and Emicida rapper.

\section{Keywords}

Celebrity, public, convocation, Instagram. 
Em julho de 2015, "Maju", a jornalista responsável pela previsão do tempo no Jornal Nacional, foi alvo de comentários racistas em uma publicação do JN no Facebook. No post foram registrados mais de 7 mil comentários, muitos com injúrias raciais como, por exemplo, "macaca", "puta africana" e "vagabunda"3. Em resposta às ofensas, a página do noticiário divulgou, no mesmo dia, um vídeo com os âncoras do jornal e a equipe de redação, lançando uma campanha de apoio através da hashtag \#somostodosmaju. O vídeo recebeu mais de 30 mil curtidas e 10 mil compartilhamentos; e a hashtag da campanha rapidamente alcançou o primeiro lugar nos trending topics no Twitter.

Após a repercussão do caso, a postagem inicial recebeu outros diversos registros apoiando Maju e defendendo que o preconceito dali fosse denunciado. Nota-se que, depois do posicionamento público da equipe célebre de jornalistas, o "caso Maju" ganhou visibilidade e provocou um tipo de engajamento em torno do preconceito racial, dentro do ambiente virtual. O episódio serve como mais um exemplo para retratar o contexto atual de intolerância das redes sociais.

A pesquisadora Raquel Recuero afirma que a presença e o alcance crescentes dessas redes na sociedade contribuem para a disseminação de radicalismos e preconceitos, que surgem como um tipo de consequência da visibilidade conquistada pelos "discursos de minorias" (como, por exemplo, a cultura negra e a homossexualidade) que, embora sempre tenham existido, não tinham tanta evidência antes de a internet se transformar em uma ferramenta tão popular e acessível. ${ }^{4}$

Considerando esse contexto virtual, a intenção deste trabalho é contribuir para a discussão acerca das possibilidades de representação das diversas faces dos anônimos, a partir do deslocamento do olhar para as novas formas de interlocução que se manifestam entre as celebridades e os comuns, no ambiente digital. Inseridas no cotidiano das mídias, as celebridades podem ser ponderadas como elementos dinâmicos do corpo social que, embora sejam consideradas "criações" midiáticas, promovem conexões sociais importantes, capazes de fazer reverberar de diversas maneiras os discursos "dominantes" e os discursos de minorias.

Para pensar a relação entre famosos e comuns dentro de um cenário composto por diversas minorias, discutiremos, primeiramente, a emergência de determinados grupos sociais que se distinguem da massa, à luz da definição de público e de sua associação com conteúdos públicos e com figuras midiáticas.

3 Trecho retirado da matéria publicada em http://zh.clicrbs.com.br/rs/noticias/noticia/2015/07/racismo-contra-majuapresentadora-do-tempo-do-jornal-nacional-gera-campanha-4794562.html, acesso em 03/11/2015.

4 Trecho retirado de matéria publicada em 21/05/2015, no site do jornal Zero Hora, disponível em: <http://zh.clicrbs.com.br/ rs/noticias/noticia/2015/05/o-discurso-de-odio-se-tornou-mais-visivel-diz-pesquisadora-4766057.html> Acesso em 01/10/15. 
A proposta é estabelecer uma noção de "público" que se difere da ideia de "audiência", a fim de avaliar o processo comunicativo a partir de uma concepção que envolve grupos sociais ativos, e não reativos, como parece ser a audiência. A intenção é refletir a respeito do impacto da mídia na constituição desses grupos sociais, analisando as tentativas de representação, por parte das celebridades, em suas convocações de públicos específicos.

Baseada nas ideias sobre público e celebridades, a segunda parte do trabalho trata de uma investigação de dois perfis célebres na rede social Instagram. Selecionamos os perfis do rapper Emicida e da cantora de axé Daniela Mercury, que parecem construir seus rostos públicos atualmente também a partir de discursos "engajados" e direcionados para segmentos sociais diferentes. Emicida afirma seu trabalho através da cultura negra e de discursos contra o racismo. Ele se coloca como o porta-voz daqueles que vivem às margens da sociedade. Daniela Mercury, depois de assumir a homossexualidade publicamente, passou a defender em seu perfil a diversidade sexual. Eles representam, no enquadramento proposto, os discursos direcionados que atingem públicos distintos. A constituição desses grupos diante da atuação da mídia é o ponto que abre a nossa discussão.

\section{A noção de público: do conceito à visibilidade da mídia}

Na tentativa de clarear a distinção entre o público e o privado, Dewey (2008) chama a atenção para os dois tipos de consequências geradas por ações humanas quaisquer: as que afetam apenas as pessoas diretamente envolvidas, e aquelas que também provocam reações em outras pessoas, além daquelas diretamente relacionadas. De acordo com o autor, no segundo caso, a ação adquire um caráter público, uma vez que as consequências indiretas são reconhecidas em um grupo de pessoas que extrapola o campo direto da ação. Ao contrário, quando as consequências ficam restritas às pessoas diretamente envolvidas nela, a ação é privada e, nesse sentido, o limite entre o privado e o público acaba sendo fixado com base na extensão e no escopo das consequências das ações, na forma como elas reverberam dentro de um contexto específico ou coletivo.

Dewey (2008) aponta que, etimologicamente, público é vinculado à coletividade, aquilo que é comum, à ideia de populus: consiste em todos aqueles que são afetados pelas consequências indiretas das ações. Pensando, então, o público como um coletivo, o autor afirma que todos os modos de comportamento associado podem ter consequências que envolvam outros, além daqueles que produziram e/ou receberam diretamente os impactos da ação. Dessa forma, Dewey (2008) estabelece uma divisão entre os universos privado e público, conferindo ao segundo uma característica de estado político, que surge como uma zona 
dada à associação de comportamentos e crenças sociais, para fins de interesses compartilhados. "Diretamente ligado aos conceitos de público e privado surge o qualificativo de coisas e/ou pessoas públicas e privadas" (FRANÇA; SIMÕES, p. 7, 2014), e, nesse sentido, os temas ou assuntos públicos são aqueles que dizem respeito a um coletivo que os ultrapassa; eles incidem sobre o comum.

Enquanto coletivo concreto, o público se refere a um grupo de pessoas ligadas por algum interesse, desejo, convicção, experiência ou ação comum. De acordo com Babo-Lança (2013, p.219), originalmente "há uma dimensão contextual e política no público que se forma graças ao desenvolvimento das comunicações". A noção de público se associa à opinião pública e a experiências e significações compartilhadas, que podem ser convertidas em uma ação conjunta para uma comunidade de interesses. No entanto, com a expansão da mídia de massa, a concepção política que era admitida no termo foi substituída pela visão de um público anônimo, passivo e subordinado. Durante muito tempo, a noção assimilada a partir dos meios de massa, especialmente da televisão, foi percebida como um conjunto de anônimos passível de manipulação.

Babo-Lança (2013) associa as perspectivas de Daniel Dayan e Jacques Ranciére para ressaltar o caráter ativo do público no contexto atual. A noção de Dayan difere audiência de público, destacando três aspectos característicos: ao contrário da audiência, que responde a uma oferta e é, portanto, reativa, o público carrega uma dimensão cênica de apresentação de si mesmo (implica em uma ação primária, de encenação e performance, que o torna ativo); o termo "audiência" delata um discurso de especialista em terceira pessoa, enquanto o público se conforma no "nós" de um dado coletivo; e por fim, o público confere uma dimensão de adesão a certos valores, ideias ou decisões que, para o autor, não pode ser sintetizado em um indivíduo e nem na soma deles, uma vez que implica sociabilidade, envolvimento e efetivação. Rancière, por sua vez, afirma que o público é ativo porque olhar é uma ação. Na visão do autor, o público age quando observa, seleciona, compara e interpreta - é um intérprete ativo, acima de tudo, que correlaciona textos da mídia com suas próprias experiências pessoais e/ou coletivas.

Tendo em vista a compreensão de um público ativo, a perspectiva de BaboLança (2013), baseada na conjuntura da sociedade midiatizada, destaca que públicos implicam uma atividade de recepção; em maior ou menor grau, uma resposta e um comprometimento. Para a autora, os públicos se constituem como formas de respostas a um acontecimento ou conteúdo público que se coloca em torno de um acontecimento midiático. Ela sublinha que existem muitas diferenças entre públicos, assim como sobreposições entre grupos que vão se formando conforme os temas debatidos na sociedade. 
Na visão de Babo-Lança (2013), o público não precede a recepção, a ação ou as performances que o visam. Ele se constitui no momento de interação, nas próprias situações de recepção, em resposta ao acontecimento ou ao problema coletivo. Ao mesmo tempo, também existe uma passividade com relação aos grupos sociais, ligada às noções de experiência e interação, que valida em determinadas comunidades um tipo de predisposição para se tornar público, no sentido engajado do compartilhamento de ideias e posições.

A autora conclui que, atualmente, como produtores e receptores de conteúdos, o público tem potencial para reativar redes de sociabilidade, mantendo a continuidade do processo de significação e atribuição de sentidos acerca dos mais variados temas que tocam a esfera pública, dentro do universo midiático. Nesse sentido, é possível pensar o engajamento instalado nas mídias sociais brasileiras como uma experiência coletiva que, além de criar comunidades passíveis de comprometimento e resposta, ressalta a dimensão contextual e política do público e a questão da opinião associada a determinados coletivos.

Os temas de interesse compartilhados por grupos específicos, como, por exemplo, os discursos de minorias, formam coletivos passíveis de engajamento, e também idealizam públicos, na medida em que são trabalhados junto à mídia em uma espécie de convocação ${ }^{5}$ que já os considera preexistentes (público de novelas, público de minisséries, público da classe $A$, etc). Do ponto de vista da produção, o discurso parece ser previamente direcionado, segmentado e associativo.

O contexto de multiposicionamentos origina, assim, opiniões e ideologias compartilhadas entre fragmentos sociais, que, aplicadas no cenário da visibilidade midiática, podem funcionar como argumentos de convocação de determinados públicos. As celebridades, enquanto pessoas públicas com capacidade para afetar a coletividade, e, ao mesmo tempo, analisadas como "fabricações culturais" (ROJEK, 2008, p. 12) que, essencialmente, dependem de uma mediação para conseguirem atrair a atenção coletiva, podem ser tomadas como um elemento chave na relação que se cria entre a mídia, a figura pública e os grupos sociais de anônimos que formam os públicos. Ainda que brevemente, é essa relação que avaliaremos a seguir.

\section{As celebridades, o engajamento social e a idealização de públicos}

$\mathrm{Na}$ intenção de entender os diversos sentidos e impactos da noção de fama e do conceito de celebridade, Turner (2004) criou três definições para o termo.

\footnotetext{
5 Neste trabalho, usamos o conceito de convocação encontrado na abordagem de Prado (2013). Ele destaca a presença de dispositivos de encontro entre produtores e espectadores na sociedade midiatizada, que atuam como aparelhos ideológicos, recortando o mundo e recolocando as posições dos sujeitos através de um discurso novo, que, insistentemente, convoca o sensível e o inteligível na pretensão de capturar a adesão do público. A ideia da convocação, de acordo com Prado (2013, p. 51), parte de paisagens e cenas que constituem mundos ficcionais, e planeja um "sujeito que responde de dentro, aderido" ao discurso e à proposta de pertencimento à comunidade que a mídia projeta. Neste caso, consideramos as celebridades as próprias enunciadoras de seus argumentos de convocação.
} 
Na primeira, o autor indica que a celebridade é um gênero de representação e um efeito discursivo, chamando a atenção para a forma como as pessoas famosas são representadas e comentadas no contexto social. Na segunda perspectiva, o foco são os processos pelos quais uma pessoa é transformada em mercadoria, observando, então, a celebridade como uma commodity negociada pela mídia.

Em sua última definição, Turner (2004) indica que celebridades são formações culturais com função social; ou seja, ele reflete o fenômeno como um aspecto da cultura, que é constantemente reescrito e reformulado. As três definições indicam que as celebridades impactam tanto nos processos desenvolvidos dentro dos produtos da mídia, quanto nas práticas sociais que se reverberam no cotidiano das pessoas. Sobretudo, as concepções de Turner (2004) evidenciam como as celebridades se colocam entre as relações da mídia e da sociedade - que, como exposto, forma seus públicos de acordo com experiências compartilhadas e através de engajamentos solicitados no contexto da esfera pública.

Seja pela exposição da vida íntima, que atende aos interesses de determinado público, seja por alguma virtude reconhecida, que desponta como valor coletivo, as celebridades se conectam aos anseios e experiências compartilhadas que constituem públicos específicos. Elas impactam na formação desses públicos porque, de certa maneira, carregam em sua própria imagem determinados valores, posicionamentos e ideologias que, enquanto uma construção cultural, já "nascem" de forma negociada entre as estruturas de produção da mídia e as predisposições de compartilhamento e engajamento dos públicos.

No quadro de posições fracionadas da mídia digital brasileira, na qual, como já dissemos, a visibilidade é apreendida como um valor, o encontro de temas polêmicos com celebridades apresenta um potencial diferenciado para transformar algo em um debate público, ainda que tenha suas origens fincadas no universo privado. Do ponto de vista da discussão social baseada na perspectiva de Dewey (2008), as celebridades ligadas a temas de interesse coletivo relevam sua função cultural enquanto catalisadoras de opiniões e críticas que estabelecem o debate público. Questões importantes como a igualdade entre raças, a homossexualidade e o aborto, parecem encontrar mais ou menos predisposições para serem debatidas, à medida que se conectam com a visibilidade de figuras públicas.

Por outro lado, como representantes de determinados públicos, as celebridades também podem se beneficiar com a visibilidade de temas coletivos, adquirida em contextos diversos. Afinal, ao personificarem ideologias e experiências coletivas, com mais ou menos visibilidade, as celebridades ganham recursos para conquistar e fidelizar públicos que, talvez, não estivessem passiveis à recepção de seus conteúdos se não fosse pelo tipo de representação que sua imagem carrega ideologicamente. 
À luz dessa contradição e tendo em vista o aporte teórico empregado, a intenção da pesquisa empírica é tentar apreender alguns esforços das celebridades para se colocarem como representantes de um certo coletivo, observando os possíveis níveis de aceitação e rejeição dos públicos, dentro da noção de uma entidade ativa e emancipada.

\section{Análise empírica: engajamento no Instagram}

Os perfis de famosos selecionados parecem encenar o empenho de representação de grupos sociais específicos, a partir da convocação de temas passíveis de adesão pública. Antes de explorar a atuação de cada um deles no universo do Instagram, no entanto, é importante retomar os pontos que mais sobressaem diante do conjunto de informações midiáticas que compõem suas imagens públicas.

Daniela Mercury é uma das mais consagradas cantoras de axé do Brasil. Em 25 anos de carreira, vendeu mais de 20 milhões de discos, venceu um Grammy Latino e recebeu mais de uma dezena de prêmios. Fez muito sucesso até o início da década de 2000 e foi apontada como a principal cantora de axé do País. Até 2006, seu status de fama era relativamente restrito à sua atuação pública e sua vida pessoal não sofria tantas especulações. No entanto, em 2007, um jornal carioca divulgou ${ }^{6}$ que Daniela estaria namorando uma arquiteta que morava em Nova Iorque e, a partir de então, a cantora passou a se esquivar dos depoimentos relacionados à vida privada. Em 2012 ela se separou do marido, com quem estava casada há três anos e, no ano seguinte, declarou um relacionamento homoafetivo por meio das redes sociais, com uma foto da parceira, dizendo: "Malu agora é minha esposa, minha família e minha inspiração para cantar".

A declaração chamou a atenção da mídia e da sociedade de tal forma que, hoje, além de "diva do axé", Daniela também é afirmada pelo público como "musa gay". Suas convocações discursivas afinadas com os apelos dos grupos LGBT, desde então, demonstram como a cantora parece orientar sua atuação de acordo com um público predefinido. No Instagram, seu perfil (@DANIELAMERCURY) possui 230 mil seguidores e mais de 1500 postagens.

Leandro Roque de Oliveira, o Emicida, foi definido pela revista RollingStone (set/2015) como a maior referência do rap para a sua geração. "Ele é um dos homens de maior destaque no país, eleito pela revista Forbes Brasil, em 2014, um dos trinta nomes mais influentes abaixo dos 30 anos" (ARAÚJO, 2015, p.52). Começou a ganhar visibilidade nos duelos de freestyle, em 2009, e, desde então, se afirma em letras musicais como um representante dos negros e das ruas, 
aquele que lembra e fala "pelos esquecidos". O último disco, lançado com seu próprio selo, é fruto de uma viagem à África e resultado de uma parceria bem sucedida com a Natura. O rapper defende a cultura negra em todos os seus canais de comunicação, destacando sua origem pobre e sua história de superação em um discurso encorpado de convocações. No Instagram, seu perfil (@emicida) possui quase 570 mil seguidores e mais de 2.500 postagens.

A fim de analisar as interações entre celebridades e públicos, tentamos estabelecer algumas categorias que pudessem facilitar a apreciação de traços comuns. Durante o mês de setembro de 2015, observamos diariamente os perfis das duas celebridades, buscando identificar a frequência de postagens e o conteúdo a que esses posts se referiam: se à vida pessoal ou a situações privadas, se ao universo do trabalho e da atuação pública, ou se eram engajados em alguma pauta coletiva. Posteriormente, trabalhamos para elencar quatro postagens principais em cada um dos perfis (uma postagem por semana), baseados no número de curtidas. Nessas postagens, examinamos mais quatro aspectos: o conteúdo das imagens; a legenda deixada pelas celebridades; os comentários dos públicos; e as respostas dos famosos aos comentários do público (se elas, eventualmente, apareciam).

No geral, foi possível perceber que o Instagram é intencionalmente transformado em uma ferramenta de divulgação da própria atuação pública, por parte das celebridades. No entanto, apesar da maioria das publicações se referirem ao trabalho dos famosos, algumas imagens não são oficialmente produzidas para a divulgação da face pública. Elas também denotam um sentido de privado, à medida que exibem os bastidores e os artistas em situações de privacidade (com parceiros, sem camisa ou sem maquiagem), como se as lentes do aplicativo servissem para mostrar o que acontece "por trás das câmeras"; nos momentos de criação daquilo que posteriormente se tornará público.

É nesse sentido que parece haver, por parte das celebridades, uma intenção de se aproximar do público mostrando conteúdos que parecem ser formulados por eles mesmos, com o objetivo de revelar traços de seu "eu privado", que, na verdade, nuançam, mas também reforçam sua visibilidade na mídia. É dessa forma que a lógica do Instagram aparenta afirmar a ausência de um mediador e o discurso da celebridade em primeira pessoa, quer dizer: a exibição de um momento privado, dentro do contexto público, parece gerar uma sensação de proximidade, porque é exibida, teoricamente, pelo próprio artista.

Nesse cenário, as celebridades possuem maneiras bastante distintas de interagir e convocar o público. O reflexo dessas diferenças se contorna na dinâmica singular de cada um dos perfis investigados - tanto com relação ao uso dos espaços virtuais quanto ao que emerge a partir deles, como veremos a seguir. 


\section{O uso dos perfis e o discurso de convocação}

Durante o mês analisado, Daniela Mercury postou 32 fotos com periodicidade irregular. No total, foram nove dias sem postagens, mas a cantora não passou mais de dois dias sem um novo post. Das 32 publicações, 10 são anúncios ou imagens oficiais de divulgação; 15 são fotos que não possuem relação explícita com o trabalho da própria cantora (e, por isso, enquadradas no grupo de posts pessoais); e duas sugerem engajamento e reflexão sobre pautas coletivas. A demais imagens (cinco) fazem referência à divulgação do próprio trabalho, mas não parecem ter sido criadas com tal finalidade?.

É curioso notar como as legendas das publicações parecem dar a ver a figura da artista falando por ela mesma, inclusive nas fotos de divulgação dos trabalhos; até mesmo os textos que acompanham os anúncios carregam um tom pessoal. Isso faz o post parecer uma iniciativa própria da cantora, e não uma estratégia desenvolvida por algum tipo de assessoria ${ }^{8}$. Em algumas legendas há posicionamentos de crenças relacionadas ao candomblé e à cultura baiana ${ }^{9}$, da qual Daniela e grande parte de seus seguidores fazem parte. Acreditamos que essa seria mais uma forma de convocação de grupos pré-definidos.

No mesmo sentido, as postagens com pautas coletivas parecem direcionar o significado da mensagem para um determinado tipo de público. A primeira dessas publicações se refere à foto de uma mulher negra amamentando uma criança branca, acompanhada de um texto em espanholio. Foi um post com um número razoável de curtidas (3.096) e repleto de opiniões positivas e elogiosas, como a imensa maioria de comentários registrada no perfil virtual da artista ${ }^{11}$. A segunda publicação que surge como pauta coletiva foi também a foto mais curtida e mais comentada de todo o mês de setembro (mais de 6.300 curtidas e 315 comentários).

\footnotetext{
7 A foto mais curtida da terceira semana, por exemplo, é uma capa antiga da revista Times, em que Daniela aparece como ícone do Rock in Rio. A capa da revista, publicada no Instagram, além de se integrar ao movimento das redes que comemorava 30 anos do evento, também colaborou para a divulgação da imagem da cantora. Mas, explicitamente, o post não tinha essa intenção - a legenda dizia apenas "homenagem \#RockinRio30anos".
}

8 Por exemplo, um anúncio de um show que estrearia no Rio de Janeiro foi acompanhado apenas pela legenda "falta pouco, Rio!!! [emoticons de flores, notas musicais]"; sem informações de venda e nenhum tipo de proposta direta ao fã.

9 "O dia está iluminado para Oxalá ficar feliz e abençoar as músicas com seu Axé. Êpa Babá!".

10 Traduzida, a frase dizia: "todo leite é branco, todo sangue é vermelho e todo ser humano tem uma alma".

11 A maior parte dos comentários são elogios e existem diversos registros positivos em outras línguas, como espanhol e italiano. No geral, algumas frases podem ser recorrentemente apreendidas, como, por exemplo: "vc é linda, amo a sua energia!"; "talentosa e maravilhosa"; "te amo". Para se ter uma ideia, na foto mais curtida da primeira semana (self sorridente e bem maquiada), foram cerca de 4.600 curtidas e quase 230 comentários - todos elogiando a cantora em algum sentido. 
Trata-se de um repost ${ }^{12}$ de sua companheira, Malu Vercosa, exibindo a imagem da família construída com Daniela Mercury e três filhas, com uma legenda extensa e engajada a favor de um novo Estatuto da Família e em benefício das reflexões acerca da adoção e dos relacionamentos homossexuais ${ }^{13}$. O nível dos comentários se manteve de acordo com o padrão do perfil: elogios e congratulações à cantora, especialmente, e também à Malu pelo posicionamento aberto e incentivador ${ }^{14}$.

Apesar disso, poucos usuários (todos homens) se posicionaram contra o depoimento, alegando questões religiosas. Eles diziam, basicamente, que Deus era contra a união homossexual e que a Bíblia provava "essa prática" como uma transgressão grave, colocando, portanto, as duas figuras públicas na condição de pecadoras (um dos termos menos ofensivos que foram usados). Em contrapartida, os fãs da cantora reagiram de maneiras variadas (às vezes também agressivas), e, assim, longas discussões iam se dilatando até o "usuário contra", tratado como invasor daquele espaço, se retirar do ambiente. A cantora chegou a interferir duas vezes nos comentários desse post: na primeira, enviou uma resposta a um dos "usuários contra", questionando o fundamento das questões religiosas e o tratamento ofensivo usado para insultar outros "usuários fãs". Na segunda, enviou uma mensagem a um fã que, extasiado, replicou o comentário confessando à Daniela que "só Deus sabe a dimensão da felicidade que [ela] causou ao [Ihe] responder!". Essa interação exemplifica a noção de proximidade que o aplicativo pode gerar na relação entre celebridades e comuns.

Apesar de não ter respondido a nenhum fã diretamente, Emicida fez alguns reposts de seguidores, exibindo o nome desses usuários como uma forma de reconhecimento público. Nesses casos, nota-se, a visibilidade também era dada ao seu novo $C D$, uma vez que a réplica dos posts se associava a uma ideia de divulgação espontânea por parte dos fãs.

No geral, a atuação do rapper é bem diferente do desempenho de Daniela Mercury - tanto que no mesmo período, Emicida postou 126 imagens: mais que o triplo de fotos publicadas pela cantora.

\footnotetext{
12 Essa é uma das formas de publicar no Instagram: um usuário pode replicar uma postagem feita por outro usuário, em sua própria página, dando os devidos créditos.

13 Partes importantes do post de Malu: "(...)Usamos essa foto para participar da campanha \#nossafamiliaexiste e, claro, além das manchetes por causa do tal do Estatuto da Família, que tem a pretensão de querer definir o que é família, percebi outro tipo de preconceito: com as crianças adotadas. Alguns títulos de reportagens diziam: Daniela e Malu posam com as filhas adotivas para a campanha \#nossafamiliaexiste! Queria saber porque não escrevem que fulano posou com seu filho BIOLÓGICO, por exemplo?! (...) Não só nossa família existe, como as crianças são nossas filhas, inclusive perante a lei, independentemente da composição genética delas. Ah, minha gente: filhos e famílias têm laços tão profundos, mas tão profundos, que os cegos de amor jamais conseguirão ver".
}

14 "Parabéns pela família linda. Consideramos justa toda forma de amor!"; muitos emoticons de corações e salva de palmas; "Linda atitude, linda família! Deus já abençoou vocês". 
O rapper ficou apenas um dia sem publicar e atingiu seu ápice com 11 postagens no dia 2 de setembro ${ }^{15}$. Ele posta de cinco a sete fotos por dia. Das 126 publicações, 41 são anúncios ou imagens oficiais de divulgação dos trabalhos ${ }^{16}$; 30 são imagens que não conferem relação explícita com o rosto público; e seis propõem algum tipo de engajamento político e/ou social. Na verdade, o perfil de Emicida aparenta ser alinhado ao discurso original do artista que, desde sua criação enquanto personagem midiatizado, é socialmente engajado e carregado de posicionamentos com potencial para convocar públicos. Em função disso, agrupamos na última categoria as postagens consideradas provocativas por serem, além das demais, carregadas de carga ideológica ${ }^{17}$.

A maioria das fotos do artista tem relação direta com esforços para a divulgação de seu último disco. Nesse ponto, é notório como o uso do aplicativo é voltado para fins de promoção da imagem pública e como o discurso (aparentemente) pessoal do rapper é atravessado por uma entonação comercial e publicitária ${ }^{18}$, que é visivelmente destinada a difundir a figura do ídolo. Ao mesmo tempo, também é interessante perceber como as legendas podem sinalizar uma possível autenticidade do post feito pela própria celebridade.

Ao contrário do que acontece com as legendas de Daniela Mercury, que quase sempre carregam um tom pessoal, as publicações de Emicida que exibem imagens de anúncios (com informações sobre hora e local de shows, com logomarcas e patrocinadores) têm uma linguagem mais "vendedora" (apesar de também ser despojada e fazer uso de gírias). As outras postagens (consideradas "pessoais") são, por muitas vezes, mais subjetivas e impregnadas de certos valores ${ }^{19}$.

15 Das 11 publicações de 02/09/2016, cinco se referiam à divulgação da participação de Emicida em um programa ao vivo, da rádio JovemPan.

16 Do conjunto de publicações analisadas, 19 foram não foram enquadradas em nenhuma das categorias porque, embora sejam vinculadas à divulgação do trabalho, não foram criadas com fins de promoção. Elas também tocam a esfera privada, porque exibem momentos de backstage - logo, revelam, em alguma medida, uma face que não está sempre disponível para o público. Mas essas postagens não podem ser consideradas pessoais, uma vez que atuam como catalisadoras da face pública do artista, por compreenderem um tipo de atuação midiática. Elas traduzem, na prática, como a fusão entre os universos público e privado se conforma na figura dos célebres. No perfil de Emicida, serve como exemplo dessas postagens a publicação de uma foto do irmão e sócio, Evandro Fioti, sem camisa. A legenda diz apenas "soul glo \#ubuntu".

17 Dois exemplos podem ilustrar o conteúdo ideológico das postagens: a primeira trata-se de uma charge baseada na fábula da Cigarra e da Formiga. As Formigas dizem que invejam a Cigarra, que largou tudo e foi viver da própria arte. Quando a Cigarra aparece, as Formigas, dissimuladas, disfarçam e a chamam de drogada e comunista. Através da legenda, Emicida afirma: "Ser feliz é pra quem tem coragem. \#ubuntu". O segundo exemplo convoca o público a partir de um discurso que fixa a consciência acerca da cultura negra: posando, de camiseta e calça larga em frente a um quadro com uma foto sua, de terno e gravata, o rapper pontua "Cansei de só os ternos serem pretos nos lugares chiques. \#ubuntu".

18 No post sobre o lançamento do CD nas plataformas digitais, a legenda também tem cara de anúncio: "Pra quem tava acompanhando o Altas Horas e ainda não conferiu nosso trampo novo, ouça 'Sobre crianças, quadris, pesadelos e lições de casa' nas plataformas de streaming [link]".

19 Em uma das poucas fotos em que está em um ambiente privado - um quarto de hotel, em cima da cama (não está posando para a foto, aparentemente está relaxado), mexendo no aparelho de som; a legenda é: "...vejo alvorada no morro fazer par com a da vitrola, É como se eu estivesse dentro daquele samba do Cartola..." \# ubuntu 
A hashtag \# ubuntu (antiga palavra africana) complementa esse caráter significativo. Ela aparece em 76 publicações de setembro (não marca os posts "comerciais") e significa algo como "sou o que sou pelo o que nós somos".

Assim como acontece com Daniela Mercury, os comentários registrados no perfil de Emicida são majoritariamente positivos ${ }^{20}$. No entanto, nota-se que há uma dinâmica diferente no público: além de enaltecerem o ídolo, os seguidores do rapper usam o espaço de comentários para interagirem entre si, especialmente nos posts que divulgam a agenda do artista (às vezes, eles chamam a atenção pelo volume de interações).

No geral, não há controvérsias ${ }^{21}$. A única postagem em que foi registrada uma discussão entre usuários foi justamente a mais curtida (13.835) e comentada (238) do mês: uma foto da entrevista de Emicida no Programa do Jô (com direito à exibição da marca da Globo). Entre o vasto número de elogios e aplausos, três usuários comentaram que o rapper seria um "vendido que vai pra Globo ser aplaudido por outros vendidos". Só uma fã respondeu aos comentários, de forma pacífica e descontraída22. Felizmente, não há registros de ofensas nem sinais de racismo.

\section{Considerações finais}

A análise empírica indica que a passividade destacada na perspectiva de Babo-Lança (2013) com relação aos grupos sociais, ligada às noções comuns de experiência e interação, pode ser aferida através da dinâmica do Instagram. Os usuários validam um tipo de predisposição para se tornar público na medida em que se agrupam a partir de gostos, interesses, valores e expectativas, que são personificados pelas celebridades e, ao mesmo tempo, compartilhados em uma rede de sociabilidade.

A passividade da conformação desses indivíduos enquanto grupos sociais, no entanto, não exclui a concepção de um público ativo, já que a lógica do Instagram implica, necessariamente, na escolha de perfis a serem seguidos. E escolher significa agir. Contudo, enquanto público, os seguidores também estão sujeitos à convocação dos discursos da mídia que, intencionados, buscam a aprovação dos grupos para o crescimento ou para a manutenção da própria visibilidade. Nesse sentido, ainda que pareçam revestidas por uma camada de mediação mais fina, como já foi dito, as interações desenvolvidas no Instagram entre celebridades e

20 Nas postagens mais comentadas, as expressões \#aruaénoiz; \#toligado; "representa, zica!"; e "mano, vc é foda" são sempre encontradas.

$21 \mathrm{Em}$ posts que divulgam os produtos do selo de Emicida, podem ser encontradas críticas sobre a atuação do artista. Em uma publicação que exibia duas calças de moletom da marca, foram encontrados comentários como "suas roupas só pra pleiboi"; "porra, Emicida [emoticons nervosos]"; "filho do capitalismo"; "tá azedando o doce, Emicida. Não vacila". Mas não há discussão entre os participantes. 
comuns não aparentam ser menos planejadas e direcionadas que os discursos da mídia tradicional.

Ao que tudo indica, Emicida e Daniela Mercury fazem uso estratégico do aplicativo porque convocam o público não apenas por meio da divulgação do trabalho na cena musical, mas, principalmente, pela carga ideológica que suas imagens sustentam; estejam elas inseridas nos universos público ou privado. Emicida convoca o público majoritariamente formado por jovens de classes baixas, politizados e conscientes do papel da cultura negra no mundo, da mesma forma que Daniela Mercury direciona seu discurso para as mulheres, os grupos LGBT e as comunidades do candomblé.

A observação dos perfis virtuais demonstra que os seguidores, constituídos como público segmentado, atendem às convocações dos famosos e conciliam opiniões e visões de mundo que vão se fechando em torno das próprias experiências compartilhadas. Quem não compartilha as mesmas crenças acaba sendo expelido do espaço. Essa lógica, além de tentar justificar um dos motivos para a ausência de debates mais profundos nas redes sociais em torno de temas coletivos, também tem a intenção de ampliar as reflexões acerca dos posicionamentos das celebridades e seu poder de afetação social. 


\section{Referências}

ARAÚJO, P. "Força Negra". RollingStone, São Paulo, n.109, p. 50-57, set. 2015.

BABO-LANÇA, I. "O acontecimento e os seus públicos". Comunicação e Sociedade, v. 23, p. 218-235, 2013.

DEWEY, J. The collected works of John Dewey, 1882-1953. Supplementary volume 1: 1884-1951. Carbondale and Edwardsville: Southern Illinois University Press, 2008.

PRADO, J. L. A Convocações biopolíticas dos dispositivos comunicacionais. São Paulo: Educ: Fapesp, 2013.

ROJEK, Chris. Celebridade. Trad. Talita M. Rodrigues. Rio de Janeiro: Rocco, 2008.

SIMÕES, P. G.; FRANÇA, V. R. V. Celebridade: quando o privado atravessa o público (e vice-versa). Revista FAMECOS, v. 21. 2014. p. 1062-1081.

TURNER, G. Understanding celebrity. Thousand Oaks, CA: SAGE, 2004.

submetido em: 14 mar. 2016 | aprovado em: 27 mai. 2016 